\title{
Marian Chace Foundation Lecture 2020 Trauma-Informed Dance Movement Therapy: Real Life Trainings with Syrian Refugees, China and US COVID-19 Hotline
}

\author{
Ilene A. Serlin ${ }^{1}$
}

Accepted: 14 May 2021 / Published online: 3 June 2021

(c) American Dance Therapy Association 2021

Hello, everyone! I am so aware that this is on Zoom and I'm trying so hard to think of the faces whom I'm addressing now, and I want to tell you how much I miss seeing you. I was so looking forward to being together in Montreal, to dancing together and hugging! So, like so many real-life situations we're all facing right now, we'll have to make the best of it with Zoom.

I want to start by thanking such dear and long-time friends for this remarkable honor. First, my intrepid friend Marcia Leventhal, with whom I have shared so many adventures. Starting with Irmgard, we created our Collective in the 70s, crossed paths through Gestalt and traipsed around China and Istanbul.

And then, a thank you to so many other women who I've long respected and admired for so long, and who are dedicated to carrying on the vision of Marian Chace. As I discover ways of working with trauma in global settings, I actually find that my early trainings with Marian Chace approaches have become a staple of the work that I share with you today for this convention's theme of global work. This training also fits so naturally into my early days as a folk dancer. From the Habonim youth group in Israel when I was 14, to studying Israeli folk dance with the great Fred Berk at the 92nd St. Y in New York in 1964, and then having the 92nd St. $\mathrm{Y}$ becoming the site of a new and flourishing dance therapy program, under Dr. Miriam Berger, more than 50 years later. Seeing the spirals of time, connections in friendships. Through Jungian training and analysis my growing understanding that archetypes are not static, but movements in life making these wonderful archetypal forms. Patterns of process. Of course, beginning with the circle and the spiral, just as Irmgard used to say. Ancient forms. So ancient and so basic that they appear in most cultures, and therefore help build bridges across cultures.

Editor Note: This lecture was presented during the American Dance Therapy Association conference that was held virtually in 2020 due to the Covid-19 pandemic. The full presentation is available via video on the American Dance Therapy Association website or here: https://youtu.be/KCvatEOR284.

Ilene A. Serlin

iserlin@ileneserlin.com

1 Union Street Health Associates, 35 Miller Ave. \#313, Mill Valley, CA 94941, USA 
It was, therefore, natural to just build on those forms to work with intergenerational trauma in a global setting. How do communities express their losses of home, family and culture? Can working within the familiarity of their culture help bring healing?

Over the course of the last twenty years, I have had the unfortunate opportunity to get more experience working with intergenerational trauma, starting in Israel in 1986 through Dr. Vivien Marcow Speiser and Lesley University. It was obvious there how the arts were already a powerful part of the healing process. After that, I had the opportunity to bring some of these healing arts to Istanbul, and then to Jordan to work with Syrian refugees. Using local dance forms and music, I was able to co-create opening and closing rituals for the conference and introduce movement into the women's support group.

I had a chance to make a training film in Jordan since our intention was not to stay but to help train the local medical and social work students. My part was to work with the training manual to describe how to lead simple support groups, and to bring in movement as one of the modalities. Since video is more effective than text, I developed a proposal for a training film (https://www.youtube.com/watch? $\mathrm{v}=$ qljMbQga7Ks). With the help and support of the Marian Chace Foundation, I was able to create a training film that would teach some of the healthcare professionals in Amman, Jordan, a simple way to bring movement into their groups.

Working in other cultures presents challenges of understanding levels of cultural complexity and communication traditions. On the other hand, these challenges are also joyful opportunities for cultural exchange and good humor. Traveling to the South of China sharing dances with the Bai people, improvising with students by the sea, by the Great Wall, learning Sufi dances in Istanbul while bringing dance therapy to people in a psychiatric hospital and in a senior center, and finding that Mayim, Mayim became one of my students' favorite warm-up are unforgettable experiences that give me hope over and over about the basic goodness of human beings and the importance of culture's role in mental health.

Then COVID hit China. Suddenly, I could not go in person, and all interaction had to be by Zoom, including our training program and supervision. In the supervision group I was hearing cases of the psychologists who were asked to staff their university hotlines and were facing new roles as short-term hotline providers.

This was the beginning of the pandemic, where people were newly shut into enclosed and often small spaces. Their shock, panic and fear sometimes manifested as aggression toward others, and the hotline counselors needed short-term tools to help them.

Therefore, we developed a film based on embodied responses to dealing with COVID related trauma. We are in the process of making others and learning about the interesting question of how to use a disembodied medium to bring forth an embodied response in others. One way is to simplify the training so that it could be used for a one-time session, or longer. The basic issues to be addressed in this case included: Normalizing, Grounding, Creating Safe Space, Boundaries and Control of the Boundaries, Creativity, Resilience, Regrowth. Some of the videos use a longer narrative in which the basic issues are addressed, but since the university students can use the hotline only a short time, this one is being used to help them and their counselors. These videos can be viewed in the full length recorded lecture on the American Dance Therapy Association website. 
The existential threat brought by the pandemic awakens us to the reality that life may never return to what we assumed to be normal or stable, and that it is essential to learn effective ways to cope with natural and manmade disasters. Dance/movement therapy is an inherently cross-cultural, connecting, expressing and healing modality that can help us with life's new normals.

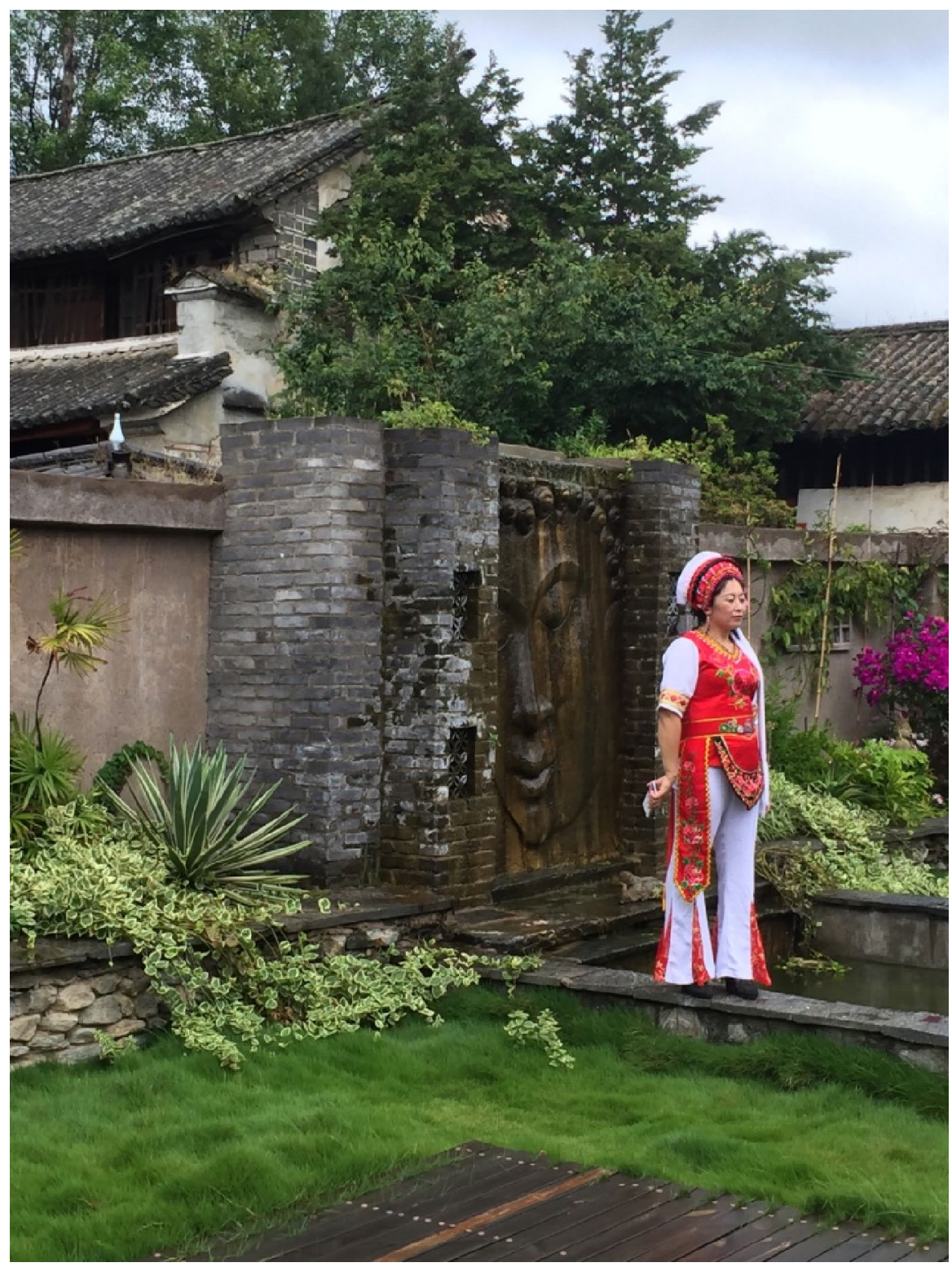

Bai Woman in Yunan Province, Photo Credit I. Serlin 


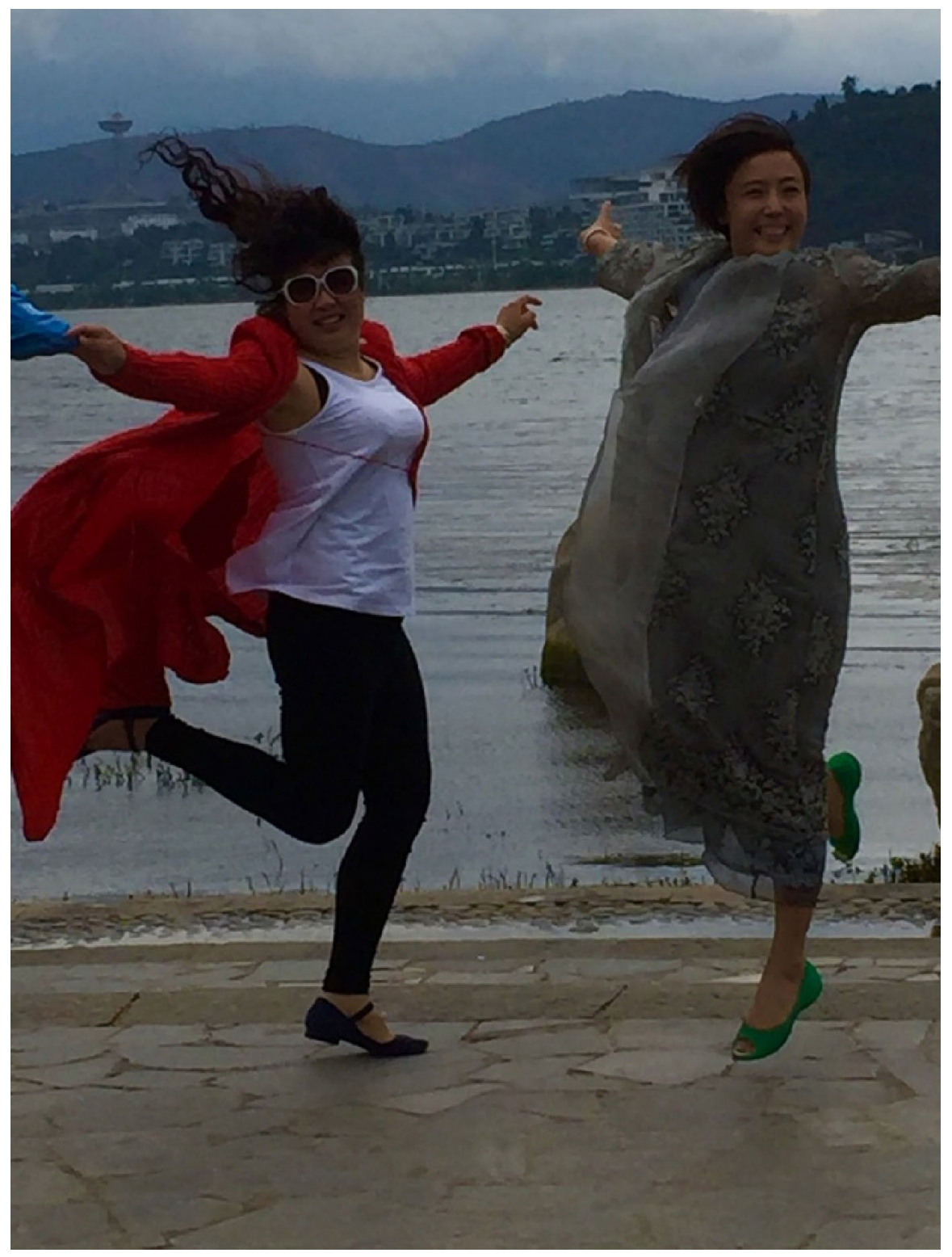

Improvisation at Chuxiong, Yunan Province, 2016, Photo Credit I. Serlin 


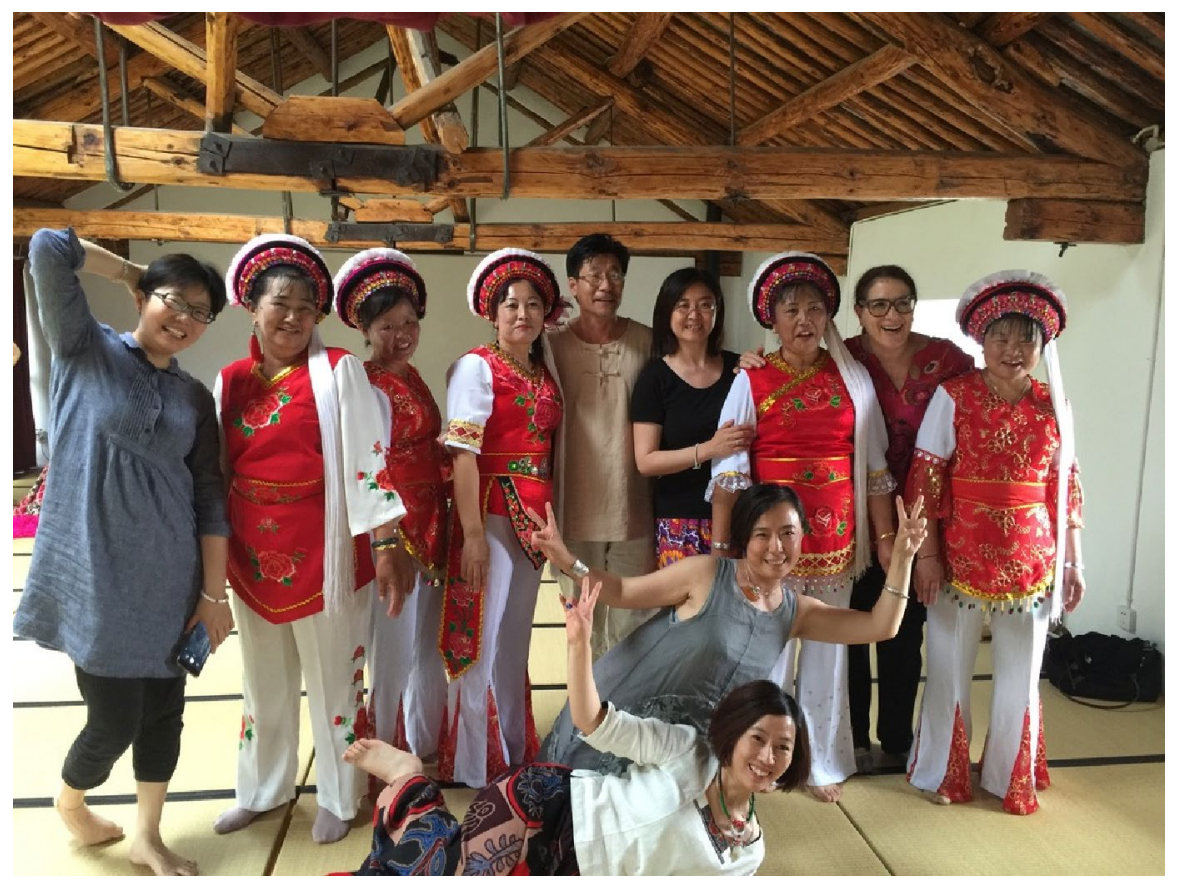

Bai Women Teaching Us Their Dances, Photo Credit I. Serlin 


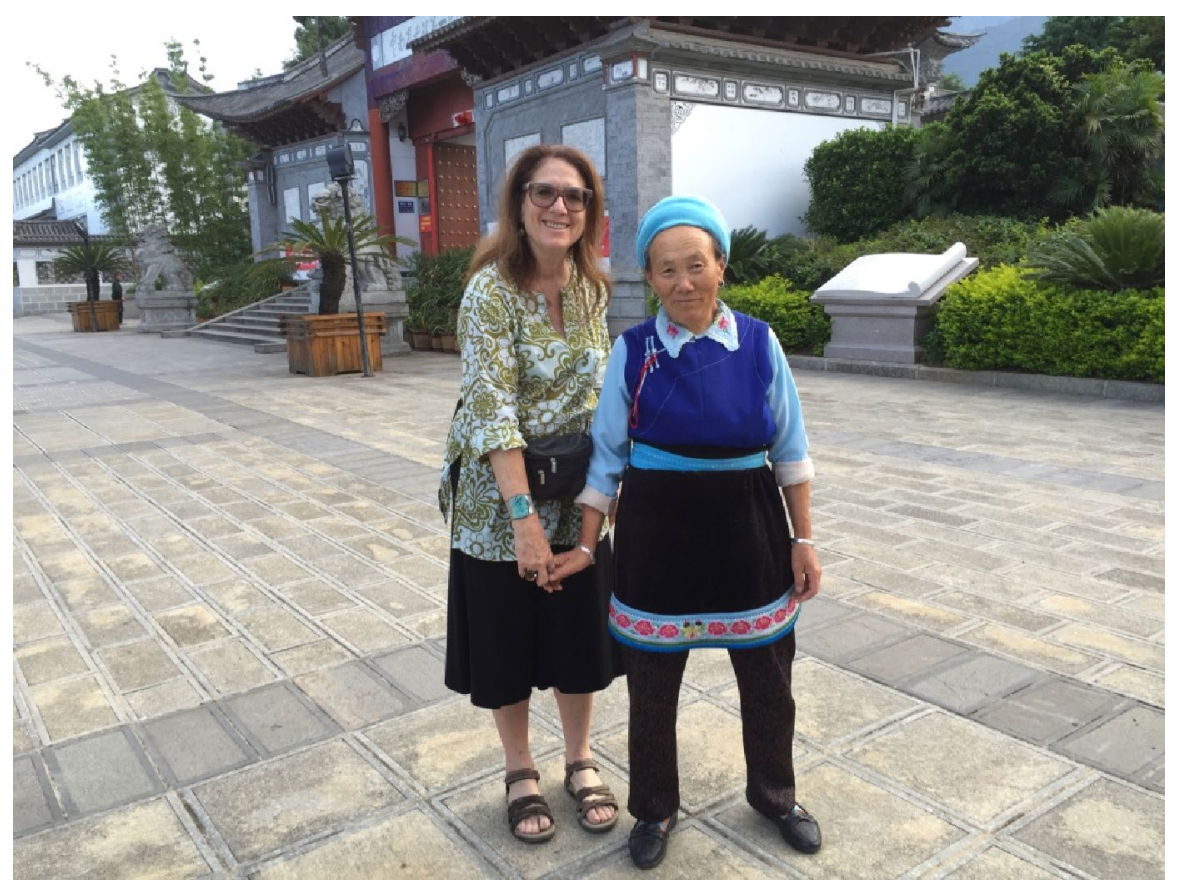

Bai Village, Photo Credit I. Serlin

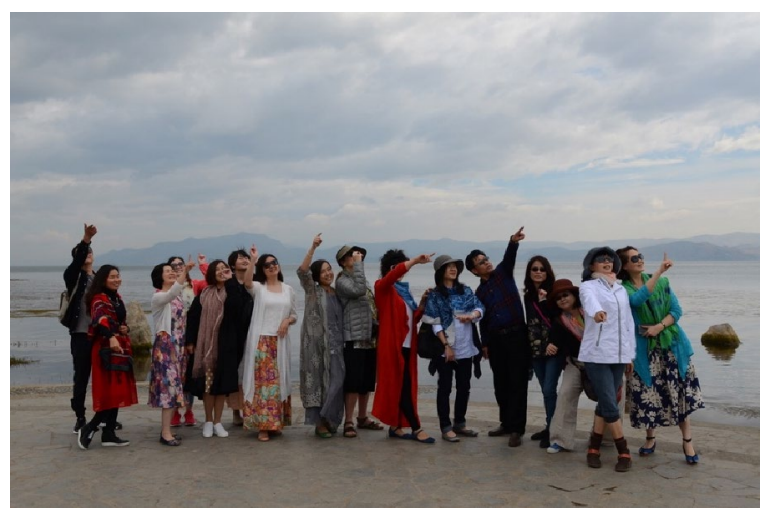

Improvisation at Chuxiong, 2016, Photo Credit I. Serlin 


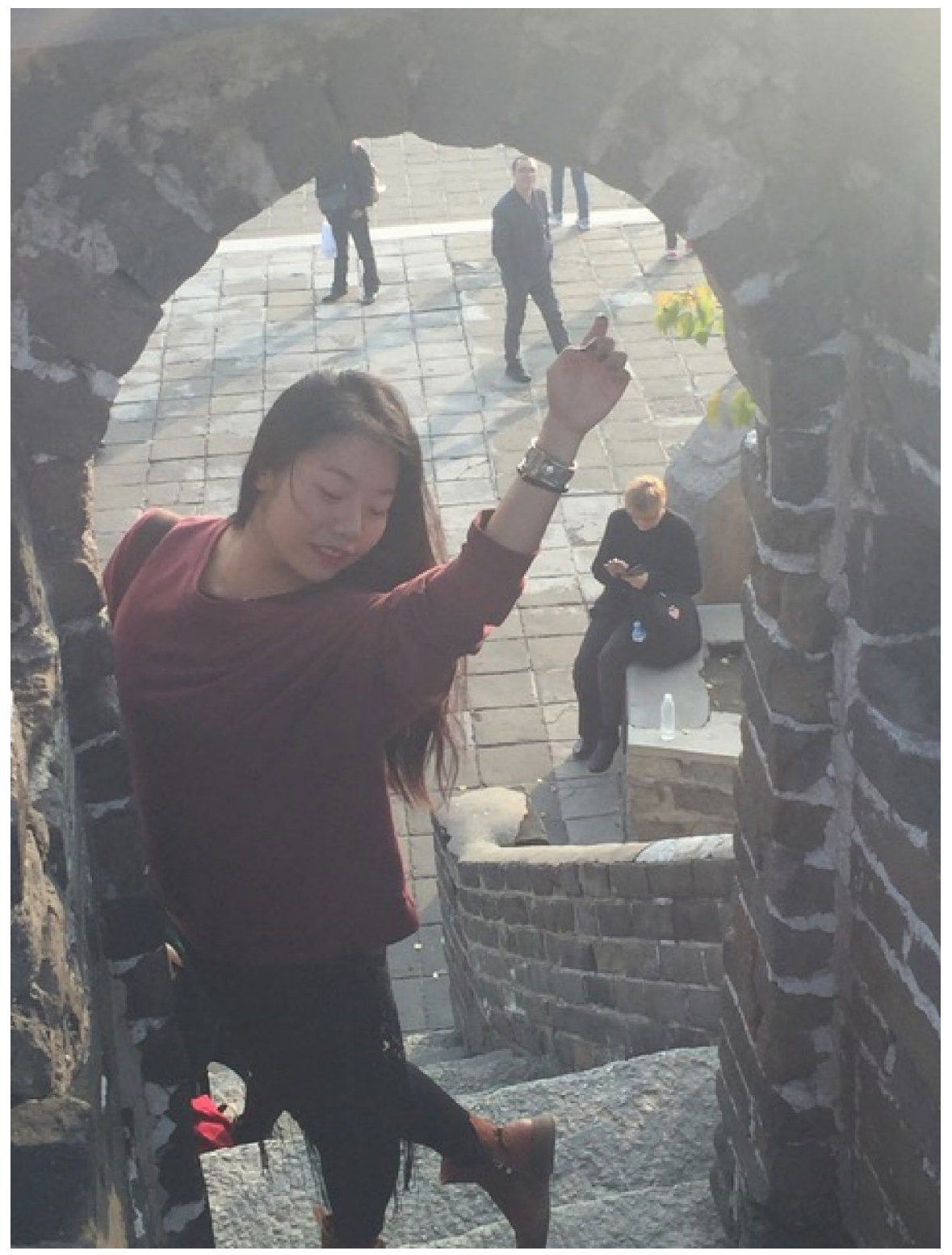

Improvisation at Great Wall, Beijing, Photo Credit I. Serlin 


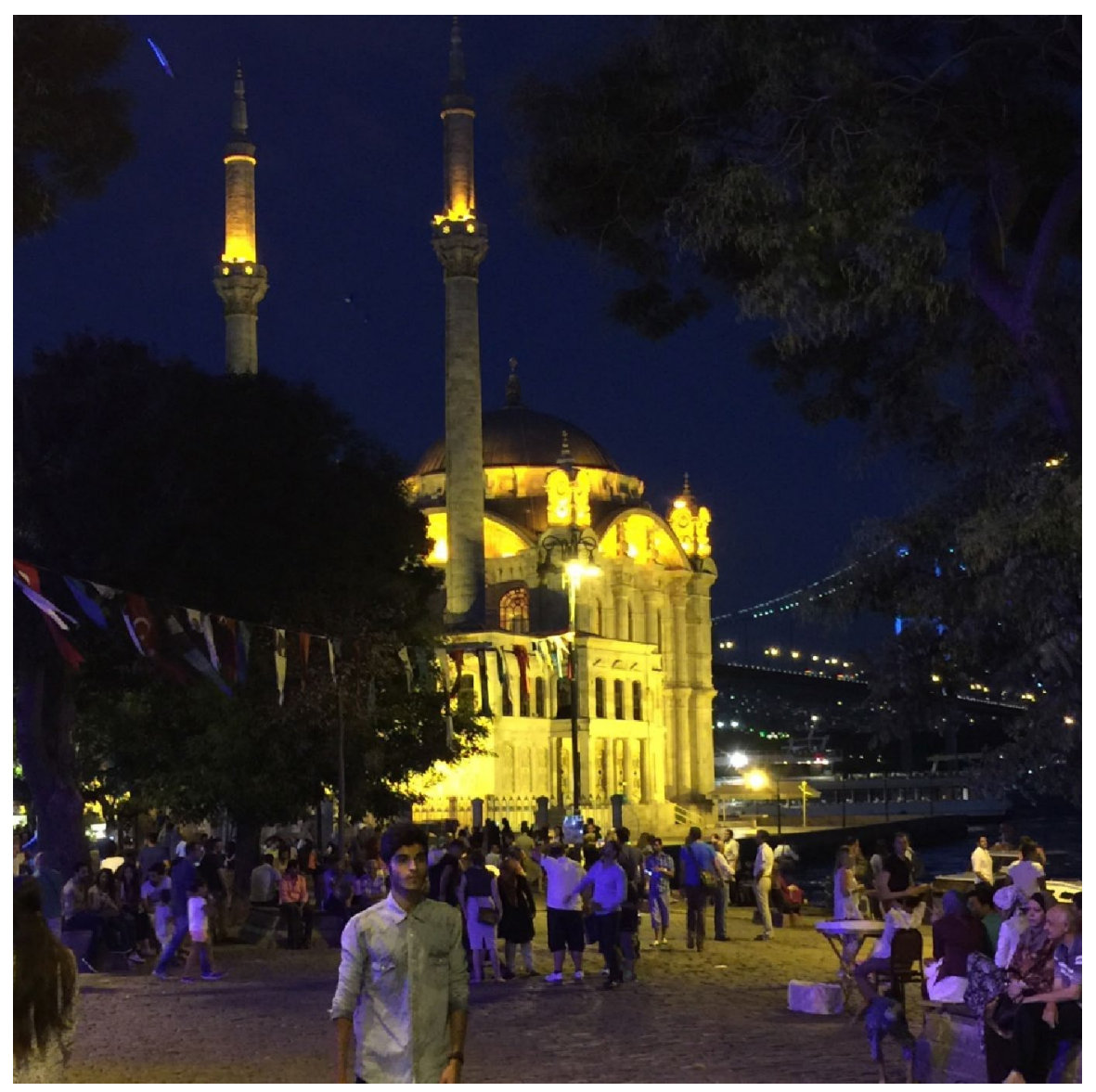

Instanbul Evening, Photo Credit I. Serlin 


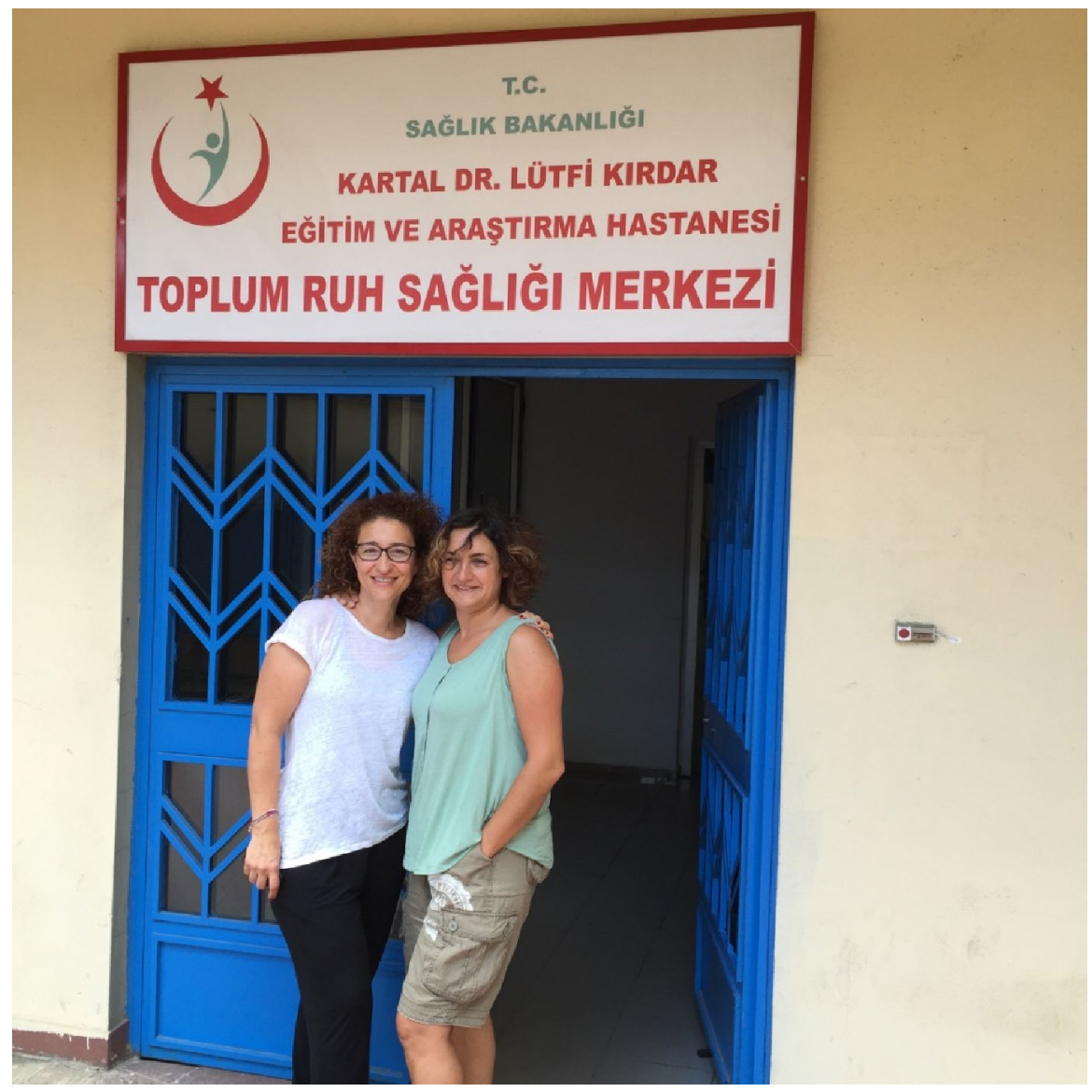

Students at Oncology Clinic, Istanbul, Photo Credit I. Serlin 

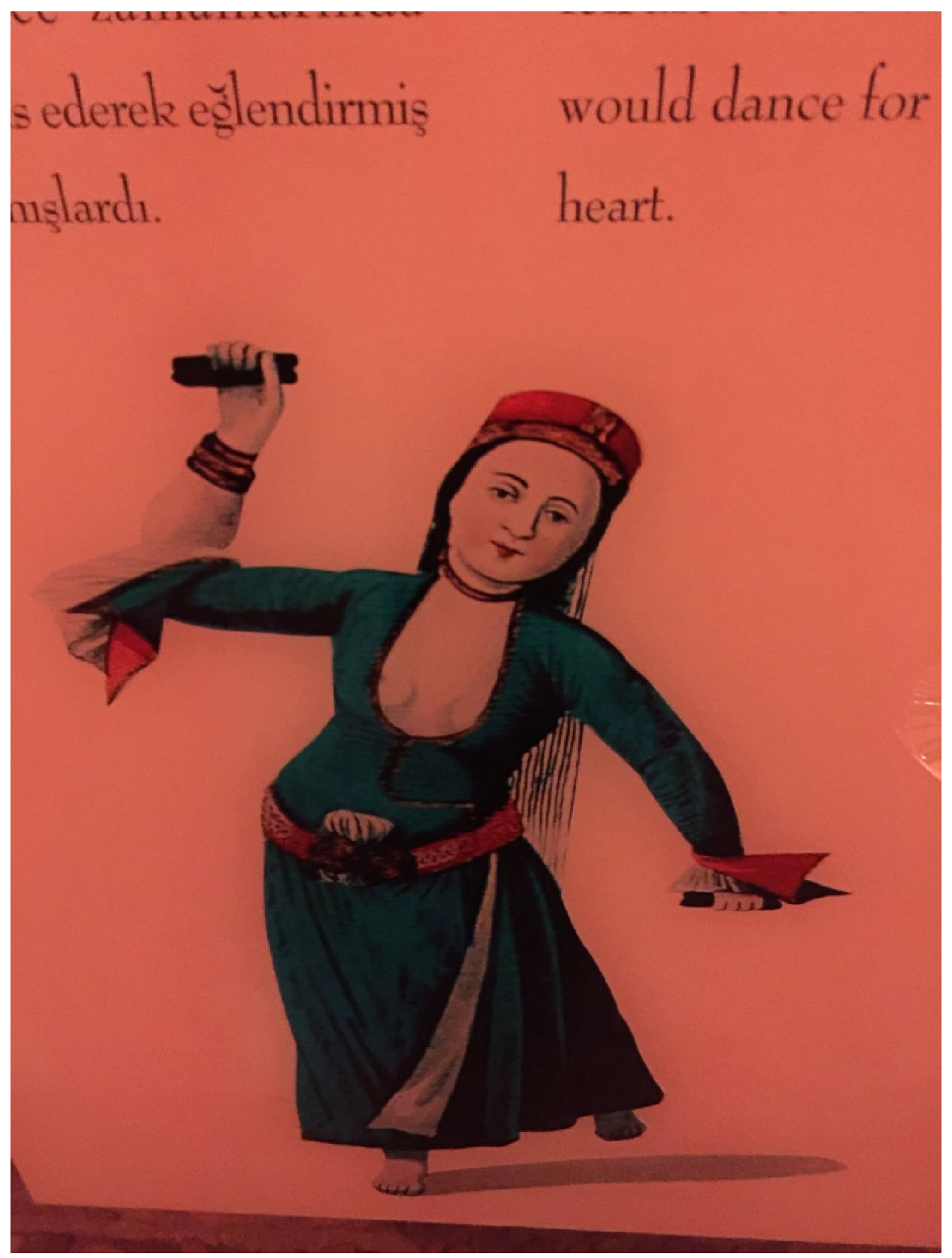

History of Turkish Dance. 


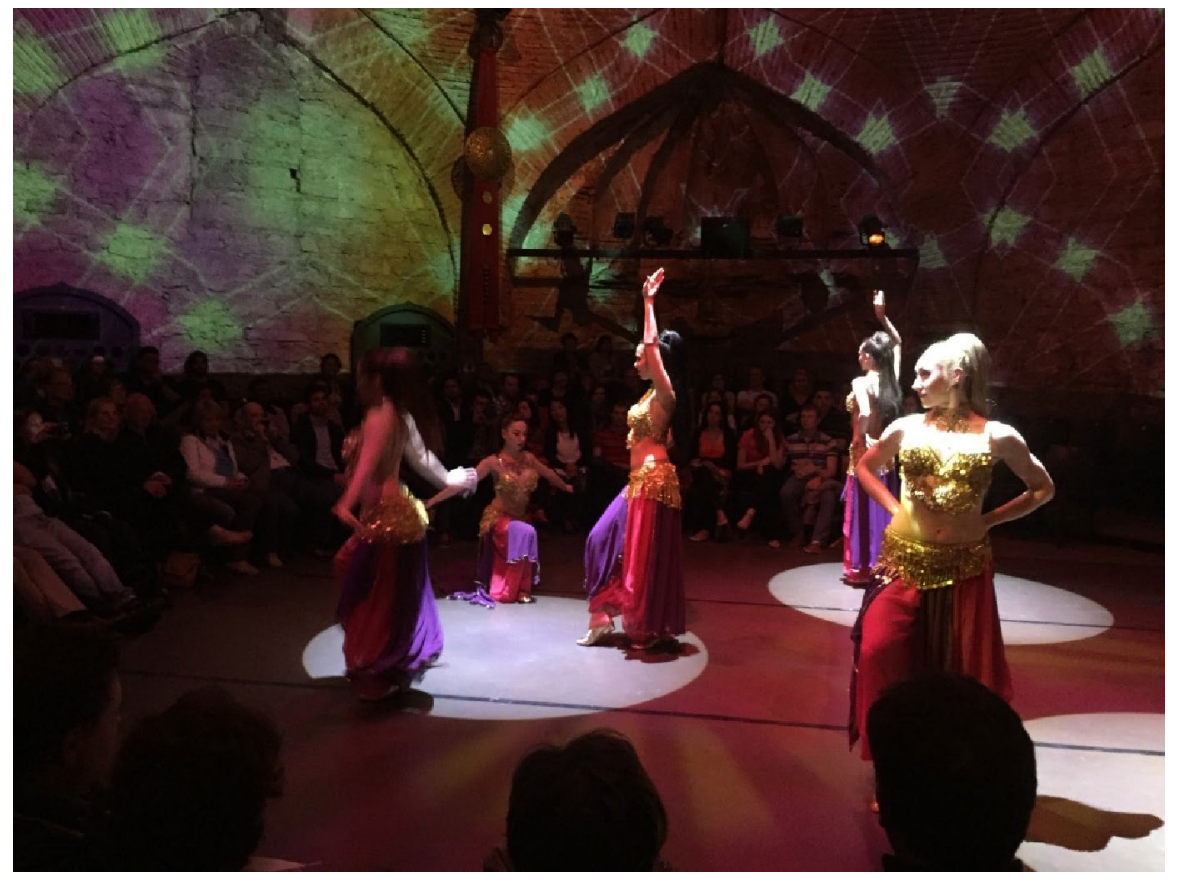

Belly Dance Performance Istanbul Photo Credit I. Serlin 


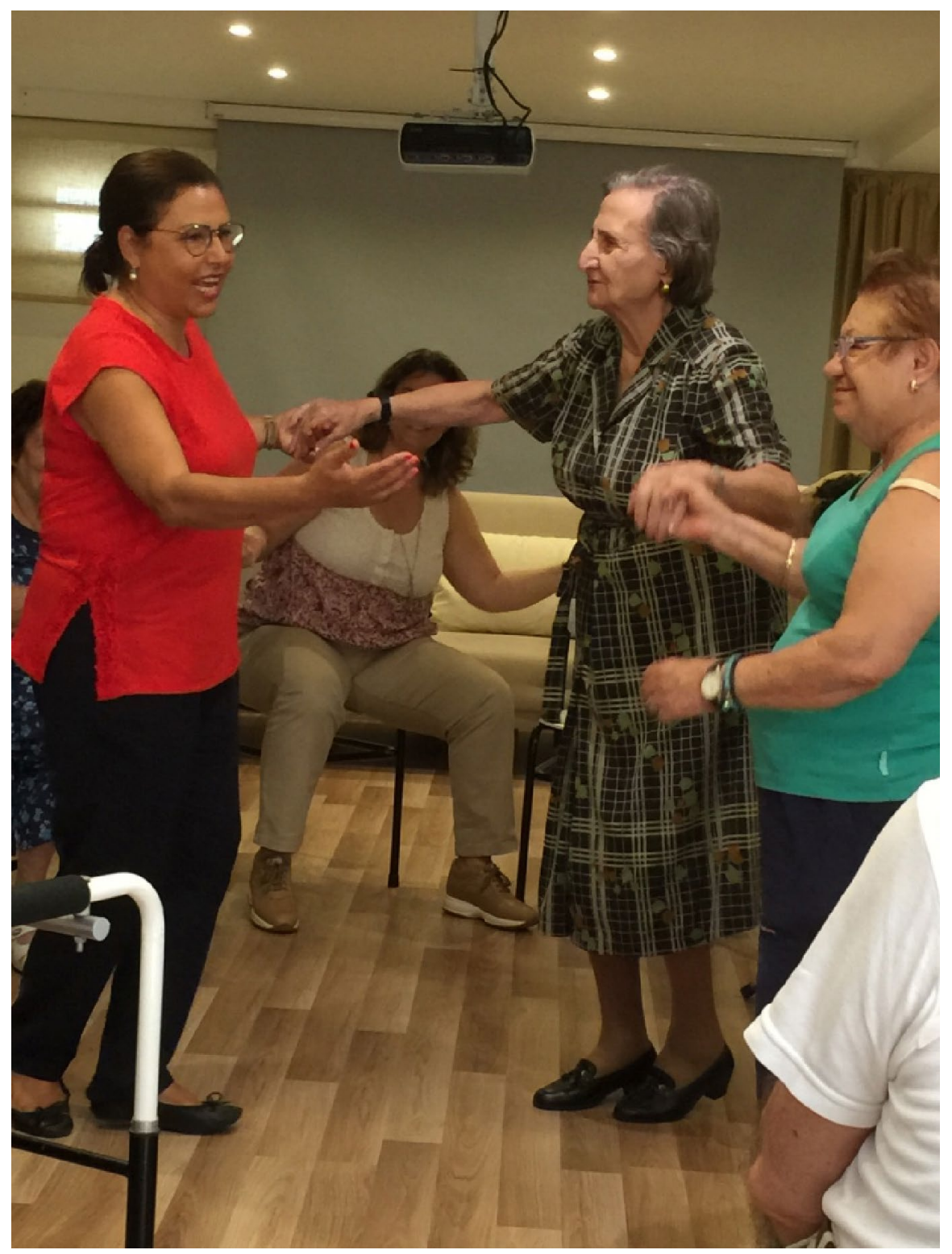

DMT in Senior Residence, Istanbul, Photo Credit I. Serlin

\section{Declarations}

Conflict of interest The author declares no conflict of interest. 
Ethical Approval This article does not contain any studies with human participants or animals performed by any of the authors.

Publisher's Note Springer Nature remains neutral with regard to jurisdictional claims in published maps and institutional affiliations. 